\title{
Efficiency Study of Vertical Distance Variations in Wireless Power Transfer for E- Mobility
}

Eftekhar, Morteza Ghorbani; Ouyang, Ziwei; Andersen, Michael A. E.; Andersen, Peter Bach; Ribeiro, Luiz A. de S. ; Schaltz, Erik

Published in:

IEEE Transactions on Magnetics

Link to article, DOI:

10.1109/TMAG.2016.2517569

Publication date:

2016

Document Version

Peer reviewed version

Link back to DTU Orbit

Citation (APA):

Eftekhar, M. G., Ouyang, Z., Andersen, M. A. E., Andersen, P. B., Ribeiro, L. A. D. S., \& Schaltz, E. (2016).

Efficiency Study of Vertical Distance Variations in Wireless Power Transfer for E-Mobility. IEEE Transactions on Magnetics, 52(7), [8401004]. https://doi.org/10.1109/TMAG.2016.2517569

\section{General rights}

Copyright and moral rights for the publications made accessible in the public portal are retained by the authors and/or other copyright owners and it is a condition of accessing publications that users recognise and abide by the legal requirements associated with these rights.

- Users may download and print one copy of any publication from the public portal for the purpose of private study or research.

- You may not further distribute the material or use it for any profit-making activity or commercial gain

- You may freely distribute the URL identifying the publication in the public portal 


\title{
Efficiency Study of Vertical Distance Variations in Wireless Power Transfer for E-Mobility
}

\author{
Morteza Ghorbani Eftekhar ${ }^{1}$; Ziwei Ouyang ${ }^{1}$; Michael A.E. Andersen ${ }^{1}$; Peter B. Andersen ${ }^{1}$; Luiz A. de S. Ribeiro ${ }^{3}$; Erik Schaltz ${ }^{2}$ \\ ${ }^{1}$ Department of Electrical Engineering, Denmark's Technical University, Lyngby, Denmark \\ ${ }^{2}$ Department of Energy Technology, Aalborg University, Aalborg, Denmark. \\ ${ }^{3}$ Institute of Electric Energy, Federal University of Maranhao, Sao Luis, Bacanga, Brazil.
}

\begin{abstract}
A Wireless Power Transfer (WPT) system is a safe, convenient and smart charging solution for Electric Vehicle (EV) users. However, a drawback of WPT systems is reduced efficiency in comparison to conventional wired charging due to lower coupling. By increasing the volume of EVs in the market, improving the system efficiency even a few percent, beside of being environmentally suitable, will benefit both consumers and distributors. According to the previous studies, efficiency improvement by decreasing the vertical distance $\left(V_{D}\right)$ between transmitter $\left(T_{X}\right)$ and receiver $\left(R_{X}\right)$ coils, has been one of the aims of the companies and universities. However, in low $V_{D}$, system performance becomes highly sensitive, due to the magnetic coupling strength. The focus of this paper is to analyze the effects of decreasing the vertical distances to WPT resonance tank efficiency's. Finally, some of the most significant parameters that affect the system efficiency at low $V_{D}$ such as quality factor and third harmonic interference are analyzed and a mitigating approach is proposed.
\end{abstract}

Index Terms-WPT; efficiency; mutual inductance; $3^{\text {rd }}$ harmonic impedance interference; reflective resistance

\section{INTRODUCTION}

$\mathrm{W}$ PT technology has a growing market potential, which in the past few years has gained a lot of attention among companies [1-2-3]. There are many companies that are developing the different types of WPT systems such as Qualcomm, Plugless, WitriCity, Delfi, Magna, Maxwell, Panasonic, Daimler, BMW, GM etc. [4-5]. However, there are only a few companies that have been producing the new technologies based on decreasing the vertical distance [6-7], with the aim of increasing the power transfer efficiency, which is the focus of this paper. For instance, the Fraunhofer Institute for Integrated Systems and Device Technology (IISB) with Nose to nose wireless charging method successfully achieved 95\% of efficiency [7], and Hughes Electronics that produced the Magne Charge for General Motors by using a magnetic paddle method achieved $86 \%$ efficiency [6].

The Magne Charge is an old example of such products with low efficiency. On the other hand, the IISB product has a considerable issue regarding the lack of standardization for placing the coils. While every company placing their transmitter and receiver coils in different places of the EV such as back bottom, middle bottom, front bottom and in the case of IISB is front nose. Thus, their products are selfdependent, which means, the costumers need their own specific charger, transmitter and receiver coils installed and won't be useful with the other applications. This leads to being unsuccessful in the market. However, the idea of decreasing the vertical distance was successful with $95 \%$ efficiency. Therefore, setting some international standardization rules for WPT systems seems a necessary task for the worldwide responsible organizations. In this paper, the mutual inductance and the efficiency of the WPT resonance tank in several different vertical distances analyzed to demonstrate the system behavior. The $3^{\text {rd }}$ harmonic interference and the quality factor effects found as complex parameters that should take into consideration as it is presented.

\section{WPT MODEL}

\section{A. WPT Coil Position Model}

In the Figure 1 the coils geometry view is designed to illustrate the coils geometry size and position. As it is shown in the figure, $V_{D}$ is the mentioned vertical distance, which is measured from the top surface of the Litz wires to the other side Litz wire surface. Ferrites are including 4 layers of $2 \mathrm{~mm}$ thickness and aluminums are also $2 \mathrm{~mm}$ thickness layer both in each sides (top and bottom).

3 Diew

Top View
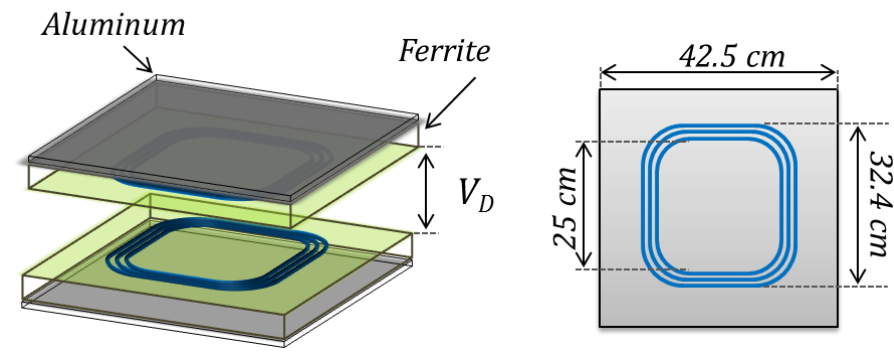

Figure 1: Coils Geometry Map

\section{B. WPT Resonance Tank Model}

The equivalent circuit model of the WPT system presented in Figure 1, is shown in Figure 2, where, $R_{P}$ and $R_{S}$ are the primary and secondary inductor and capacitor internal resistances respectively; $M$ is the mutual inductance; $R_{L o a d}$ is the equivalent load resistance; $Z_{P}$ and $Z_{S}$ are the primary and secondary impedances respectively. The main purpose of this study is analyzing the WPT resonance tank behavior as it defined in Figure 2, while the vertical distance is decreasing.

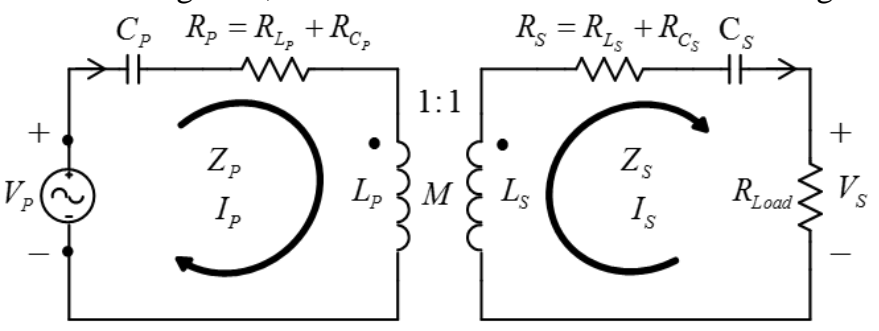

Figure 2: WPT system schematic

The analyses implemented are based on two different approaches. Firstly, the safe mode analyses, through RLC meter measurements, which are related to applying the low power in the system. This method is providing the study with the main knowledge about the system and its behavior while the magnetic coupling is changing due to the vertical distance 
variations. Secondly, the On-Load experimental analysis, which is related to applying the high power in the system. This method is also providing the study a chance to analyze the system behavior under the high power, which is always include some more complexities such as harmonic interferences, and distortions that is discussed in the following sections.

According to the first approach, all of the variable values including the primary and secondary inductances and their internal resistances are measured through the RLC meter in nine different vertical distances $\left(V_{D}=1,2,3,4,5,6,10,14\right.$ and $18 \mathrm{~cm})$. All measurements have been implemented in the linear sweeping frequency $(1 \mathrm{kHz}-130 \mathrm{kHz})$ to analyze the system behavior. Furthermore, the capacitance values for primary and secondary sides, assumed to be constant $\left(C_{P}=C_{S}=215 n F\right)$ while the project focus is to analyze the system behavior according to coil's vertical distance variations.

\section{WPT Equivalent Circuit Model}

One of the most important parameters that affect the WPT system's performance is the reflected resistance $\left(R_{R}\right)$ of the system [8]. The $R_{R}$, is the equivalent resistance of the load across the primary voltage, which is producing the same amount of current that would flow in the primary side due to the load connected to the secondary. In the Figure 3, the equivalent circuit of the WPT system according to reflective resistance is shown.

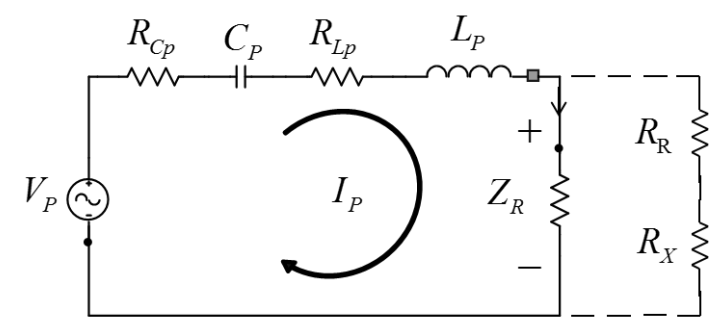

Figure 3: Equivalent WPT circuit considering the reflective resistance

According to the Figure 3 , the reflective impedance $\left(\mathrm{Z}_{\mathrm{R}}\right)$, which is including the $R_{R}$ and reflective reactance $\left(\mathrm{R}_{\mathrm{X}}\right)$, is calculated through Equation (1). When the system operates in resonance, the value of the $\mathrm{R}_{\mathrm{X}}$ is equal to zero [8]. In addition, the values of $R_{P}$ and $R_{S}$ are ignored in this calculation since their values are small and negligible comparing to $R_{\text {Load }}$. As long as they influence the efficiency as a form of loss, they are used in the efficiency calculations, which is discussing later.

$$
Z_{R}=R_{R}+R_{X}=\frac{\omega^{2} \times M^{2}}{Z_{S}}+0
$$

Where, $Z_{S}=\left(j \omega L_{S}+\frac{1}{j \omega C_{S}}+R_{\text {Load }}\right)$ is the secondary impedance. By substituting the above equation to $Z_{R}$, when the system operates in resonance $\left(\omega=\frac{1}{\sqrt{L_{S} C_{S}}}\right)$, the value of $\mathrm{R}_{\mathrm{R}}$ can be calculated through Equation (2).

$$
R_{R}=\frac{\omega^{2} \times M^{2}}{R_{\text {Load }}}
$$

\section{EXPERIMENTAL DISCUSSIONS AND RESULTS}

\section{A. Mutual inductance calculation method}

In order to measure the mutual inductance of the WPT system, first of all the self-inductances of the system is measured $\left(\mathrm{L}_{\mathrm{P}^{-}}\right.$ $\mathrm{L}_{\mathrm{S}}$ ). Then RLC meter is connected to the coils in two different positions due to the flux linkage direction difference. In this approach, the primary and secondary coils are connected in series in two different coils configuration directions as it is shown in Figure 4(a) and Figure 4(b).

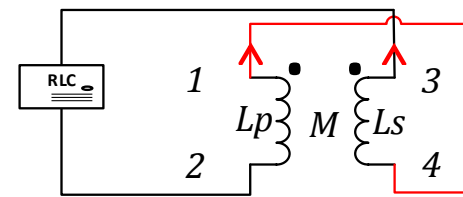

(a)

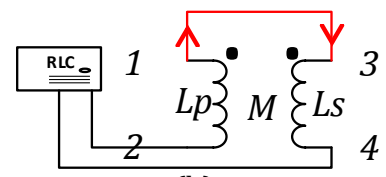

(b)
Figure 4: Circuit connections - (a) L+2M; (b) L-2M

When the two coils are connected together as Figure 4(a) configuration, which their flux linkages are in the same direction, i.e. additive [9]; the measurements so called $\mathrm{L}+2 \mathrm{M}$ and the measured value is implemented in the Equation (3) to find the related mutual inductance $\left(\boldsymbol{M}_{\boldsymbol{L}+2 \boldsymbol{M}}\right)$.

$$
L+2 M=L_{P}+M_{L+2 M}+L_{S}+M_{L+2 M} \Rightarrow M_{L+2 M}=\frac{L+2 M-L_{P}-L_{S}}{2}
$$

Similarly, the same approach is implemented to calculate the mutual inductance correspond to L-2M (Figure 4(b)), which the flux linkages of the coils are in opposite directions and is used to calculate the related mutual inductance $\left(\boldsymbol{M}_{\boldsymbol{L}-2 \boldsymbol{M}}\right)$.

$$
L-2 M=L_{P}-M_{L-2 M}+L_{S}-M_{L-2 M} \Rightarrow M_{L-2 M}=\frac{L-2 M-L_{P}-L_{S}}{-2}
$$

According to the measurements, the mutual inductances of the specific $V_{D}$ at the specific switching frequency are achieved. This approach named as $\mathrm{L}+2 \mathrm{M}$ and $\mathrm{L}-2 \mathrm{M}$. The average of both measurements will be count as an achieved mutual inductance as Equation

(5). This is due to the accuracy and preventing from the hysteresis loss, which can cause different value of mutual inductances following different coils turning direction.

$$
\bar{M}=\frac{M_{L+2 M}+M_{L-2 M}}{2}
$$

Based on the presented calculation approach, all the measured values are implemented into the explained equation through Matlab and plotted out to illustrate the mutual inductance behavior while the $V_{D}$ is decreasing. According to the results, the mutual inductance, behaves as a constant value in the frequency range used in the experiments. Hence, Figure 5 is used to illustrate the mutual inductance variation as a function of $V_{D}$, at $f_{r}=21.5 \mathrm{kHz}$. As it is shown, the mutual inductance increases significantly by decreasing the $\mathrm{V}_{\mathrm{D}}$.

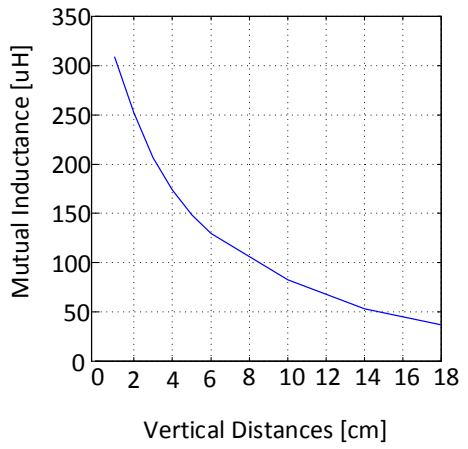

Figure 5: Mutual inductance in different $\mathrm{V}_{\mathrm{D}}$ at $f_{r}=21.5 \mathrm{kHz}$ 


\section{B. Fundamental Based Efficiency Analyses}

According to the mutual inductance analyses, it can be seen that by decreasing the $V_{D}$, the magnetic coupling strength is significantly increasing, which is affecting the system efficiency and some other elements. Therefore, through the efficiency $(\eta)$ Equation (6) [8-10], the maximum efficiency of $97.36 \%$, at $V_{D}=1 \mathrm{~cm}$ at $f_{r}=21.5 \mathrm{kHz}$, has been achieved for the WPT resonance tank, which is shown in Figure 6.

$$
\eta=\eta_{P} \times \eta_{S}=\frac{\frac{\omega^{2} \times M^{2}}{R_{S}+R_{\text {Load }}}}{R_{P}+\frac{\omega^{2} \times M^{2}}{R_{S}+R_{\text {Load }}}} \times \frac{R_{\text {Load }}}{R_{S}+R_{\text {Load }}}
$$

Where: $\eta_{P}$ and $\eta_{S}$ are the efficiencies of primary and secondary side of the resonance tank respectively; $R_{\text {Load }}=\frac{\omega_{r} \times L_{S}}{Q_{S}}$ is the load equivalent resistance; $L_{S}$ is the secondary coil inductance; $Q_{S}$ is the quality factor of the secondary side, which is assumed to be $Q_{S}=4$ as it is shown in Figure 6.

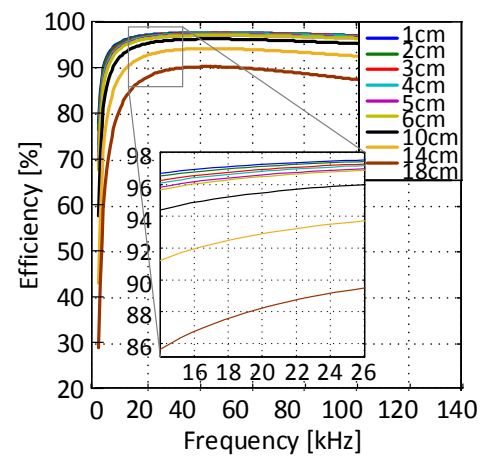

Figure 6: Efficiency plot of WPT resonance tank at $\mathrm{Q}=4$

\section{C. $3^{\text {rd }}$ Harmonic Impedance Interference}

By applying power to the system at the vertical distances below four centimeters, the system became interfered with the third harmonic impedance $\left(Z_{3^{\text {rd }}}\right)$. One of the general consequences of the $Z_{3^{\text {rd }}}$ in the system is the electromagnetic interference (EMI) that can affect the other nearby sensitive electronic devices' operation. However, the main consequence of this interference is decreasing the efficiency through higher harmonic current in the system.

Basically, in a WPT system, the first harmonic is the fundamental harmonic that will be used to transfer the power. The $2^{\text {nd }}$ harmonic and all even order harmonics are not in the system because the input voltage has square wave symmetry; hence, it will be equal to zero. The third harmonic is the undesired harmonic that interferes with output power and has to be eliminated. Based on the studies in [8], the performance of the WPT resonance tank is highly dependent on the $R_{R}$ in the way that has to stay in maximum level of $Z_{R}$, otherwise it will damp the resonance in the system. In the case we are studying, this effect appears as the $Z_{3^{r d}}$.

In order to prevent the system from this interference, it is important to clarify in which circumstances the system becomes interfered and when it will get back to the normal state. Based on the studies done in this project, it is shown that the system is interfered due to decreasing the quality factors ( $Q_{P}$ and $Q_{S}$ ) of the system below the minimum. According to the analyses, the bandwidth of the system is equal to $B W=10$
$\mathrm{kHz}$ and $f_{r}=21.5 \mathrm{kH}$. Therefore, the minimum quality factor of the system can be calculated through Equation (7).

$$
Q=\frac{f_{r}}{B W}=\frac{21.5}{10}=2.15
$$

On the other hand, the primary $Q$ can be computed through Equation (8).

$$
Q_{P}=\frac{\omega_{r} L_{P} R_{e q}}{\omega_{r}^{2} M^{2}}=\frac{\omega_{r} L_{P}}{R_{R}}=\frac{x_{L_{P}}}{R_{R}}
$$

Through the discussion it is clear, which to keep the Equation (7) hold true, the value of $x_{L_{P}}$ have to stay two times bigger than $R_{R}$. In Figure 7, the variability of two $R_{R}$ based on $(Q=$ 2 and 4), versus $x_{L_{P}}$ in different vertical distances, is illustrated. By considering the green line $(Q=2)$ in comparison to red $\left(x_{L_{P}}\right)$, it can be seen that $x_{L_{P}}$ is greater than $2 \times R_{R}$ at $V_{D}>4 \mathrm{~cm}$.

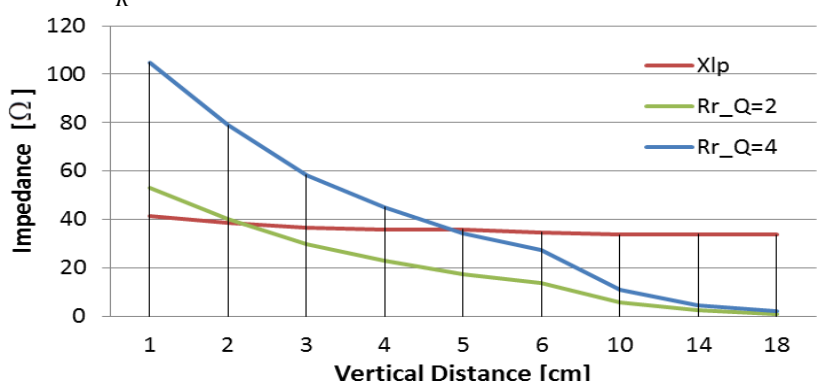

Figure 7: $x_{L_{P}}$ vs. $R_{R}$ as a domain of $V_{D}$

As long as $Z_{3^{\text {rd }}}$ is proportional to the correspond third harmonic current $\left(I_{3^{r d}}\right)$, when this value decreases, the value of $I_{3^{r d}}$ will increase. Therefore, if $Z_{3^{r d}}$ decreases to the point that Equation (7) would not hold true, thus the results will appear in the output as an interference. In the Figure 8, the efficiency of transferred power is 3D plotted in terms of frequency and vertical distances for the quality factor of four. As it can be seen, the interferences are continuing up to $V_{D}=$ $10 \mathrm{~cm}$.

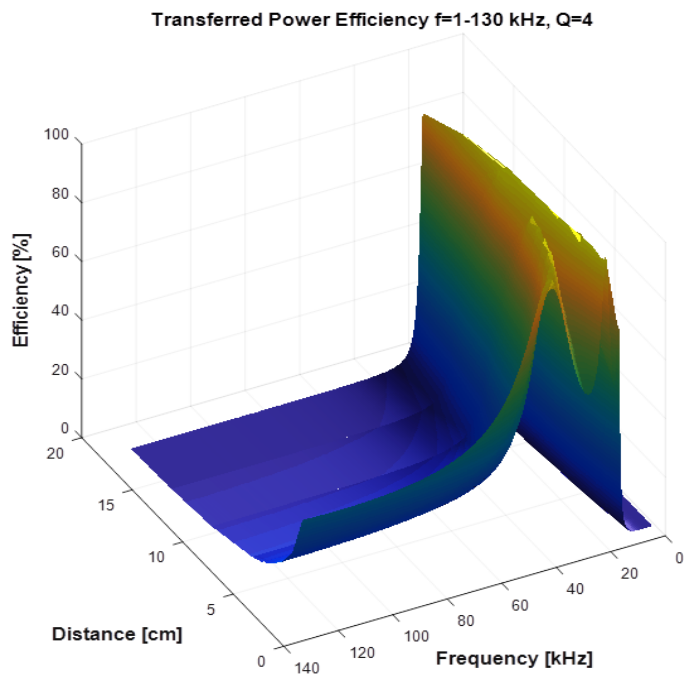

Figure 8: 3D plot of transferred power as a domain of frequency and $V_{D}$ at $Q=4$

D. On-Load Analyses

According to the analyses, it is expected to have the $3^{\text {rd }}$ harmonic interference in the vertical distances below $V_{D}=4$ $\mathrm{cm}$. Therefore, the experimental analyses have been made to prove the theoretical results. Firstly, Figure 9 is captured, which is the oscilloscope screen and the results of applying 
power at $V_{D}=1 \mathrm{~cm}$ and the operating resonance frequency calculated for the specific $V_{D}$ that is $f_{r}=18.065 \mathrm{kHz}$. Through the figure, it is clear that $Z_{3^{r d}}$ is interfering with the both primary and secondary currents differently. This is due to the different quality factors in both sides, which leads to $Z_{3^{r d}}$ behaving differently.

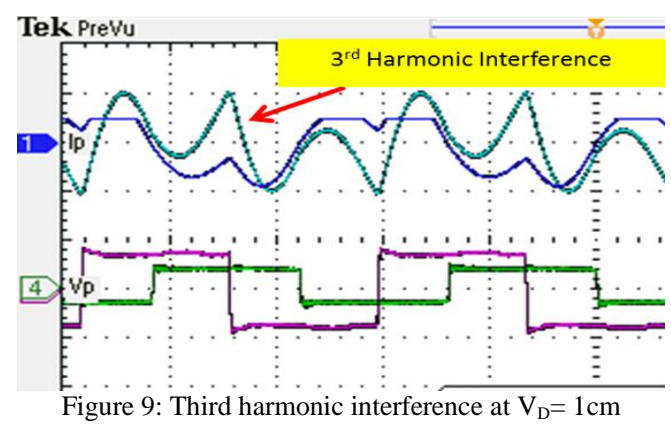

Several more experiments have been implemented to prove the quality factor effects and illustrate the interference in the system. In Figure 10, which is the results of applying power at $V_{D}=4 \mathrm{~cm}, f_{r}=20.367 \mathrm{kHz}, Q_{P}=2.53$ and $Q_{S}=1.28$, it can be seen that the interferences are decreased significantly and the primary quality factor, tuned to stay over two for the $Q_{P}$, which leads to the primary current with no interference, while the secondary quality factor is less than two and secondary current is interfered. Furthermore, the quality factors for Figure 11 is tuned for $Q_{P}=1.26$ and $Q_{S}=2.66$, resulting in the currents behaving oppositely.

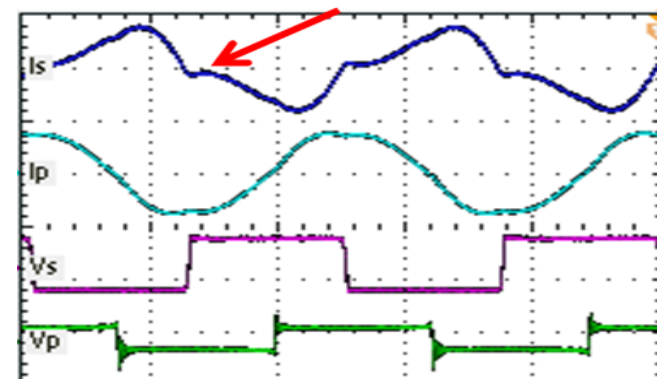

Figure 10: $\mathrm{V}_{\mathrm{D}}=4 \mathrm{~cm}, \mathrm{Q}_{\mathrm{S}}<2, \mathrm{Q}_{\mathrm{P}}>2$ and $\mathrm{I}_{\mathrm{S}}$ interfered

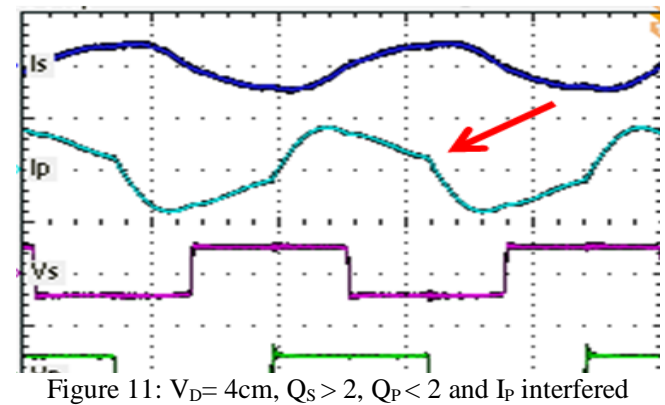

IV. CONCLUSION

Based on the results, we can conclude that, in order to keep the system with no interference the quality factors of the system have to stay at least over two in the tight coupling applications. The significance of the $Q$ and $R_{R}$ has been discussed. According to the $R_{R}$ equation, it can be seen that by decreasing the vertical distance, the mutual inductance increases significantly, which leads to increasing the $R_{R}$. This increment will damp the resonance in the system, which leads to less efficiency. Therefore, the $x_{L_{P}}$ will be smaller than the $R_{R}$ value in the distances below four centimeters, which also leads to the interference in the system.
Mainly, by decreasing the coil geometry size, the coil selfinductance will decrease [11]. Therefore, one of the effective approaches to reduce the mutual inductance in low vertical distances is to reduce the secondary coil geometry to smaller size, which is leading to smaller secondary self-inductance and thus smaller mutual inductance. However, smaller secondary coil requires new design based on the new coil's configuration.

Finally, reducing the coil geometry will cause a lot of the benefits such, the costs of the Litz wire and ferrite will be less, the occupied space on EV will be less etc.

Furthermore, these results are case dependent and might not apply in the other WPT setups, which have different designs.

\section{ACKNOWLEDGMENT}

Hereby, I would like to thank Dr. Erik Schaltz; and Aalborg University (AAU), which gently gave me the opportunity to work on their WPT setup and offered me the necessary equipment to make the measurements and analyses. A special thanks also to Dr. Luiz A. de S. Ribeiro, with his friendly advises and technical supports.

This project is supported by Denmark's Technical University (DTU), Department of Electrical Engineering, under the supervision of Dr. Ziwei Ouyang, Prof. Michael A.E. Andersen and Dr. Peter B. Andersen.

\section{REFERENCES}

[1] B. Choi, J. Nho, H. Cha, T. Ahn and S. Choi, "Design and implementation of low-profile contactless battery charger using planar printed circuit board windings as energy transfer device," IEEE Transactions on Industrial Electronics, vol. 51, no. 1, pp. 140-147, Feb. 2004

[2] J. Su, "Technical and environmental impact of electric vehicles in distribution networks.," 2014 International Conference and Utility Exhibition.

[3] Elliott G., Raabe S, Covic G. A., Boys J.T. "Multiphase Pickups for Large Lateral Tolerance Wireless Power Transfer Systems". IEEE Transactions on Industrial Electronics. vol.57, no.5, pp: 1590-1598, 2010 .

[4] A. Kurs, A. Karalis, R. Moffatt, J. D. Joannopoulos, P. Fisher, and M. Solja ci' c, "Wireless power transfer via strongly coupled magnetic resonances,” Sci. Exp., vol. 317, no. 5834, pp. 83-86, Jun. 7, 2007.

[5] A. Karalis, J. D. Joannopoulos, and M. Solja ci' c, "Efficient wireless non-radiative mid-range energy transfer," Ann. Phys., vol. 323, no. 1, pp. 34-48, Jan. 2008.

[6] MagneCharge, "WM7200 Inductive Charger Manual, GM ATV, 1998.".

[7] Fraunhofer Institute for Wind Energy and Energy System Technology IWES in Kassel (IISB), "Nose-to-nose wireless charging," 09 Aug 2014. [Online]. Available: http:// www.fraunhofer.de

[8] X. Liu, N. W. M. and L. C. K., "Optimal operation of contactless transformers with resonance in secondary circuits," in Twenty-Third Annual IEEE Applied Power Electronics Conference and Exposition (APEC '08), 2008.

[9] J. Bird, Electrical Circuit Theory and Technology, Routledge, Taylor and Francis Group. (2014) [Book]

[10] Penno, Robert; Thomas, Erin; Heebl, Jason, et al. "Comprehensive Analysis and Measurement of Frequency-Tuned and Impedance-Tuned Wireless Comprehensive Analysis and Measurement of FrequencyTuned and Impedance-Tuned Wireless Non-Radiative Power-Transfer systems," IEEE Antennas and Propagation Magazine — 2014, Volume 56, Issue 4, pp. 44-60

[11] Hochmair, E S; Zierhofer, C M, "Geometric approach for coupling enhancement of magnetically coupled coils" IEEE Transactions on Bio-medical Engineering - 1996, Volume 43, Issue 7, pp. 708-14 